\title{
Using Bayesian state-space models to understand the population dynamics of the dominant malaria vector, Anopheles funestus in rural Tanzania
}

Halfan Ngowo ( $\nabla$ hngowo@ihi.or.tz )

Ifakara Health Institute https://orcid.org/0000-0003-2789-0261

Fredros Oketch Okumu

Ifakara Health Institute

Emmanuel Elirehema Hape

Ifakara Health Institute

Issa H Mshani

Ifakara Health Institute

Heather M Ferguson

University of Glasgow

Jason Matthiopoulos

University of Glasgow

\section{Research Article}

Keywords: Anopheles funestus, State space model, population dynamic, seasonality, abundance, density dependence

Posted Date: January 10th, 2022

DOI: https://doi.org/10.21203/rs.3.rs-1209027/v1

License: (c) (i) This work is licensed under a Creative Commons Attribution 4.0 International License.

Read Full License 
1 Using Bayesian state-space models to understand the population dynamics of the

2 dominant malaria vector, Anopheles funestus in rural Tanzania

4 Halfan S. Ngowo ${ }^{1,2^{*}}$, Fredros O. Okumu ${ }^{1,2,3,4}$, Emmanuel E. Hape ${ }^{1,2}$, Issa H. Mshani, ${ }^{1,2}$,

5 Heather M. Ferguson ${ }^{1,2}$, Jason Matthiopoulos ${ }^{2}$

$6 \quad *$ Corresponding author

7

8

18 Email address:

19 1. Halfan Ngowo: hngowo@ihi.or.tz

202 2. Fredros Okumu: fredros@ihi.or.tz

21 3. Emmanuel Hape: ehape@ihi.or.tz

22 4. Issa Mshani: imshani@ihi.or.tz

23 5. Heather Ferguson: Heather.Ferguson@glasgow.ac.uk 
Abstract

Background: It is often assumed that the population dynamics of the malaria vector Anopheles funestus, its role in malaria transmission and the way it responds to interventions are similar to the more elaborately characterized An. gambiae. However, An. funestus has several unique ecological features that could generate distinct transmission dynamics and responsiveness to interventions. The objectives of this work were to develop a model which will; 1) reconstruct the population dynamics, survival, and fecundity of wild An. funestus populations in southern Tanzania, 2) quantify impacts of density dependence on the dynamics, and 3) assess seasonal fluctuations in An. funestus demography. Through quantifying the population dynamics of An. funestus, this model will enable analysis of how their stability and response to interventions may different from that of An. gambiae s.l.

Methods: A Bayesian State Space Model (SSM) based on mosquito life history was fit to time series data on the abundance of female An. funestus s.s. collected over 2 years in southern Tanzania. Prior values of fitness and demography were incorporated from empirical data on larval development, adult survival and fecundity from laboratoryreared first generation progeny of wild caught An. funestus. The model was structured to allow larval and adult fitness traits to vary seasonally in response to environmental covariates (i.e. temperature and rainfall), and for density dependency in larvae. We measured the effects of density dependence and seasonality through counterfactual examination of model fit with or without these covariates.

Results: The model accurately reconstructed the seasonal population dynamics of An. funestus and generated biologically-plausible values of their survival larval, development and fecundity in the wild. This model suggests that An-funestus survival and fecundity annual pattern was highly variable across the year, but did not show consistent seasonal trends either rainfall or temperature. While the model fit was somewhat improved by inclusion of density dependence, this was a relatively minor effect and suggests that this process is not as important for An. funestus as it is for An. gambiae populations. 
Conclusion: The model's ability to accurately reconstruct the dynamics and demography of An. funestus could potentially be useful in simulating the response of these populations to vector control techniques deployed separately or in combination. The observed and simulated dynamics also suggests that An. funestus could be playing a role in year-round malaria transmission, with any apparent seasonality attributed to other vector species.

Key words: Anopheles funestus, State space model, population dynamic, seasonality, abundance, density dependence.

\section{Introduction}

Anopheles funestus is one of the major malaria vectors in Africa and is widely distributed across the continent [1,2]. With the exception of Anopheles gambiae s.s, the species appears to have higher vectorial capacity than many other members of the An. gambiae s.l. complex [3-8]. Anopheles funestus makes a higher contribution to transmission than An. gambiae s.l. in numerous parts in sub-Saharan Africa [6,912]; particularly in settings where An. gambiae s.l. abundance has plummeted due to either effective indoor-based vector control interventions [13,14] or environmental change. It is hypothesized that An. funestus persistence despite the recent scale-up of insecticide-treated nets may have been facilitated by their earlier development of strong physiological resistance [15].

Anopheles funestus is typically grouped with An. gambiae s.l. when modelling transmission and formulating policies for malaria vector control [16-18]. The lack of explicit consideration of An. funestus ecology and transmission potential may be partially due to this species having been relatively neglected compared to An. gambiae s.l. Comparatively the ecology of An. funestus s.l is less well understood, and it is much more difficult to maintain under insectary or semi-field conditions [19]. However, this species has several unique ecological features, such as its different larval habitat and dry season persistence [20], that could give rise to distinct population dynamics and differentiate its response to core and supplementary 
interventions. For example, Anopheles funestus prefers larger aquatic habitats that are semi-permanent or permanent throughout the year, and contain clear water with some emergent vegetation [20]. This differs from An. gambiae s.s which generally prefer small temporary habitats such as puddles, ditches and animal hoof prints etc. $[20,21]$, or An. arabiensis, which can breed extensively in rice fields and other sunlit open pools [1]. The use of more permanent larval habitats means that An. funestus has greater persistence through the driest periods of the year compared to An. gambiae sl. [22] whose habitats evaporate quickly in the absence of rainfall $[21,23]$. This ecological feature means that the seasonal phenology of An. funestus and its response to aquatic microclimate differs from An. gambiae sl. [21,22,24]; and could thus generate differential response to seasonally-targeted interventions such as Indoor Residual Spraying (IRS) and larviciding.

Differential use of aquatic habitats may also impact the relative importance of key intrinsic drivers of mosquito population dynamics such as density dependence. Density dependence in malaria vectors occurs during larval development as a product of competition for space and nutritional resources [25,26]. In space-limited habitats, high larval densities can influence larval development rates and survival but also subsequent adult fitness traits such as body size, survival, fecundity and mating success [27-30]. While there is evidence that density dependence is an important driver of An. gambiae s.l population dynamics [25], the relative importance of this process for An. funestus is unknown. Given that larval crowding and competition are less likely within the larger habitats preferred by An. funestus, we hypothesize that density dependence may be less pronounced for this vector species. Quantifying the strength of density dependence is important to inform the ease with which vector populations can be suppressed and how quickly they can recover $[26,27,31]$.

Models of vector population dynamics and their response to interventions must be parameterised by reliable estimates of their demography and fitness. For vectors in the An. gambiae s.l. group, such estimates are often acquired from insectary and semi-field studies [32-37] as well as field studies. Similar data has been difficult to 
121 obtain for An. funestus because of its poorly understood ecology and the difficulties

122 of creating laboratory colonies; which so far has been achieved on only two occasions

$123[11,19,38]$. State-space models (SSM) provide an alternative approach to indirectly

124 estimate these parameters by fitting a population dynamics model to observed time

125 series data $[39,40]$. These models are widely used in other fields of ecology and

126 conservation biology to investigate the population dynamics of other animals (e.g.

$127[39,41])$ and guide management decisions [41]. However, these models have so far

128 had limited update in medical entomology. Given data on population fluctuations are 129 available, these models can infer and estimate plausible demographic rates that could 130 generate the observed dynamics [42].

SSMs are time-series models that distinguish between two stochastic components, namely, process (i.e. biological), which captures sequential dependencies between population components (e.g. eggs, larvae, pupae etc.) and an observation component, which captures and corrects for biases and imprecisions in the data-collection process. Prior knowledge of the model parameters is used to bolster the information content of the time series data with existing expert or lab data and uncertainty in estimates. Population projections are then quantified on the basis of posterior probability distributions for parameters and population states. SSM models have recently been used to elucidate the dynamics and impacts of interventions on malaria vectors in laboratory and semi field populations [32,33], but have not yet been applied to estimate An. funestus vector demographics in the wild. Here, we present an innovative SSM application to describe the population dynamics of wild An. funestus populations in Tanzania, and use it to assess extrinsic (environmental) and 145 intrinsic (density dependence) drivers of their fitness and demography for the first time. We incorporate empirical data from laboratory experiments on An. funestus 147 colonization [19] together with the wild population data to develop an SSM. Time 148 series field data collected in 2015 [6] and 2018 south-eastern Tanzania, and 149 corresponding environmental information were used to validate the model. Specific 150 aims were: 1) to accurately reconstruct the population dynamics, survival and 151 fecundity of wild An. funestus populations in southern Tanzania, 2) quantify the 
152 effects of density dependence on the dynamics, and 3) to identify and quantify 153 seasonal variations in An. funestus demography.

154 Methods

\section{Time series data on wild An. funestus populations}

156 Indoor densities of female An. funestus s.l adults were recorded over 12 months of 157 entomological surveys conducted in three villages (Tulizamoyo, Ikwambi and Sululu) in 158 Kilombero $\left(8.1539^{\circ} \mathrm{S}, 36.6870^{\circ} \mathrm{E}\right)$ and Ulanga $\left(8.3124^{\circ} \mathrm{S}, 36.6879^{\circ} \mathrm{E}\right)$ districts, south159 eastern Tanzania from June 2018 to May 2019. The villages were selected because of 160 the high abundance of An. funestus s.l; within which An. funestus s.s. is the dominant sibling species (93\%) [1]. Annual rainfall was $1200 \mathrm{~mm}-1800 \mathrm{~mm}$, and temperature, 20 ${ }^{\circ} \mathrm{C}-32{ }^{\circ} \mathrm{C}$. CDC Light traps [43] were used to sample host-seeking mosquitoes from $6 \mathrm{pm}$ to 6 am for 5 days per week, 4 weeks a month for 12 months in 10-15 houses per village. The houses were randomly selected and consent obtained from household heads. The mosquitoes were sorted by taxa and sex, and females further classified as unfed, blood-fed or gravid. Daily climatic data (rainfall and temperature) were obtained from a weather station, approximately $\sim 20 \mathrm{~km}$ from the farthest village.

To complement this data, we extracted An. funestus data from a 2015 dataset from three other villages in Ulanga district (Mavimba, Minepa and Kivukoni) [6]. These data were collected five days per week for a period of 12 months. This data allowed us to

172 fit the model simultaneously to multiple time series so that it could learn 173 hierarchically from An. funestus trajectories enfolding in different years and 174 locations. This additional data has previously been described elsewhere and used to 175 demonstrate the epidemiological dominance of An. funestus, which now contributes $176>85 \%$ of all malaria infections in the region [6].

\section{Prior information on life-history and gonotrophic cycle stages}

179 Female An. funestus adults collected from the same three villages in 2018 were maintained in insectary conditions for one generation to estimate baseline fitness

181 traits as already described in Ngowo et al [19] and in Figure 1. Data collected from 182 this $1^{\text {st }}$-generation laboratory progeny included: a) proportions of eggs that hatched 
183 into larvae, larvae that transitioned to pupae, and of pupae that emerged into adults, 184 b) the length of the transition periods (days) between life stages ((i) Eggs to $1^{\text {st }}$ instar larvae, (ii) $1^{\text {st }}$ instar larvae to pupae, and (iii) pupae to unfed adult female (one day post emergence)), c) transition period of adult females between three different stages of their gonotrophic cycle, i.e. unfed, blood-fed and gravid.

The gonotrophic cycle starts with 'unfed' females who transition to 'blood-fed' after obtaining a blood meal. In the wild, the first gonotrophic cycle usually starts after unfed females have mated [44]; which is assumed to happen soon after emergence. In insectary experiments, females had access to males immediately on emergence. As the blood meal is digested, blood-fed females transition into the 'gravid' state during which eggs develop. Gravid females then oviposit their eggs into aquatic habitats and return to the 'unfed' stage with the cycle begins again (Figure 1). In the wild, the rate of transition between these gonotrophic stages is governed by both intrinsic and extrinsic environmental conditions including the availability of blood-meals and oviposition sites [45]. In the insectary, the first blood-meal was offered 5 days post emergence to ensure individuals had sufficient time for mating.

Per capita fecundity was defined as the number of eggs laid per fully bloodfed adult female. The proportions surviving between life-history stages or gonotrophic stages were calculated as the inverse of the number of days required to transit from one stage to the next:

$$
s_{m}=\left(j_{m}\right)^{1 / r}
$$

Here, $m$ is the life cycle stage, $j$ is proportion survived as the percentage of the total from preceding life stage, $r$ is the average number of days it took to transit from one life stage to another, and $s$ is the daily survival within the stage (Table 1).

\section{Biological process components of the Bayesian SSMS}

Daily survival: The daily survival of larval stages was assumed to be the same for all instar stages. Adult survival was assumed to be the same for unfed, blood-fed and 
214 gravid females. Survival probabilities $\left(s_{l}, s_{a}, s_{f}, s_{v}\right)$ were linked to their covariates 215 through a logit transformation of linear predictors (here, subscripts $l, a, f, v$ refer to 216 larvae, unfed, blood-fed and gravid respectively). Pupal $\left(S_{p}\right)$ and egg $\left(S_{e}\right)$ survival 217 probabilities were considered to be independent of any climatic and density218 dependent covariates, and were treated as a binomial distribution, with baseline 219 rates assigned priors as described in eq. 16-17.

220

221

A range of covariates hypothesized to be associated with the demography of An. 222 funestus were incorporated to allow baseline larval and adult survival to vary with 223 environmental conditions. Rainfall (current and 1 week-lagged) and temperature were 224 incorporated into the larval survival model. Rainfall regulates the availability and 225 permanence of aquatic habitats, thus influencing both survival and carrying capacity 226 of larval habitats [46]. We also incorporated density dependence into the model of 227 larval survival [25] to assess whether this could improve the fit of the adult 228 population dynamics model. Additionally, the speed of larval development was modelled as a function of temperature based on its known importance $[47,48]$. The 230 daily survival of larvae was thus defined as a function of daily rainfall (current and 231 lagged), daily temperature and density dependence. We estimated the daily survival rates (lowercase $s_{l}(t)$ ) of larvae through a logit transformation of linear predictors 233 (uppercase $S_{l}(t)$ ).

$$
s_{l}(t)=\frac{\exp \left(S_{l}(t)\right)}{1+\exp \left(S_{l}(t)\right)}
$$

234

235 Specifically, $S_{l}(t)$ is written as a function of both intrinsic and extrinsic drivers: 236

$$
S_{l}(t)=\beta_{0}-\beta_{1} R_{(t-1)}-\beta_{2} D_{(t-1)}\left(1-\frac{\beta_{3} Q_{(t-1)}}{\max (Q)}\right)+\beta_{4} T_{(t-1)}-\beta_{5} T_{(t-1)}^{2}+\varepsilon_{l, t}
$$

237

$$
\varepsilon_{l} \sim \operatorname{Normal}\left(0, \sigma_{l, t}\right)
$$


239 Here, $\beta_{0}$ is the baseline daily larval survival on the linear scale. We assigned a prior to survival probability under zero rainfall and average temperature (i.e. $27^{\circ} \mathrm{C}$ ) and then calculated the intercept of $\beta_{0}$ to reflect this prior information. When there is no

242 effect of any environmental covariates (prior takes values between $0.80-1$, Table 1 ).

243 The coefficient $\beta_{1}$ quantifies the effect of current rainfall $(R)$; with the envisioned 244 scenario being that higher $R$ (i.e. flooding) tends to wash away larvae hence reducing 245 the baseline survival [49]. This $\beta_{1}$ was defined by an informative gamma prior with 246 shape $=5.382$ and rate of 46.4 (Table 2 ) which permits anything from no rain effects 247 to $100 \%$ mortality. The coefficient $\beta_{2}$ quantifies the effect of larval density at time $t$ 248 on larval survival. We assume a monotonic negative relationship based on the 249 biologically-plausible hypothesis that larval survival is reduced at high larval density 250 because of resource competition and intraspecific cannibalism [29,50]. This 251 coefficient $\beta_{2}$ was defined by an uninformative gamma prior with shape of 0.5 and 252 rate of 1 (Table 2 ), which allows the impact of density to range from no effect to 253 complete annihilation.

254

255

The term inside brackets in Eq. (3) represents the fact that density dependence needs to be modulated by the availability of larval habitat. The availability of suitable 257 aquatic habitats for oviposition will increase with rainfall; thus potentially reducing 258 the crowding of larvae into the remaining habitats that persist during the dry season. This hypothesis has been supported for An. gambiae sl., where their seasonal 260 population dynamics can be explained by models incorporating a rainfall-dependent carrying capacity [25]. Here, the coefficient $\beta_{3}$ was a proportion that captures the 262 potential interaction between larval habitat availability (defined as the cumulative 263 rainfall $(\mathrm{Q})$ over the past week) and larval density $(D)$. When rain in the recent week 264 has been the maximum observed (i.e. $Q=\max (Q))$, then $\left(1-\frac{\beta_{3} Q_{(t-1)}}{\max (Q)}\right)$ would be the 265 smallest amount of density dependency experienced by An. funestus. The prior 266 distribution for $\beta_{3}$ was defined by an upward-biased beta prior with mean 0.9 and 267 variance of 0.01 allowing $\beta_{3}$ to have positive impact on larvae survival. 
269

270

271

272

273

274

275

276

277

278

279

280

281

282

283

284

285

286

287

288

289

290

291

292

293

294

$$
S_{f}(t)=\theta_{0}+\theta_{1} T_{(t-1)}-\theta_{2} T_{(t-1)}^{2}+\varepsilon_{f, t}
$$




$$
S_{v}(t)=\alpha_{0}+\alpha_{1} T_{(t-1)}-\alpha_{2} T_{(t-1)}^{2}+\varepsilon_{v, t}
$$

296

297

$$
\varepsilon^{*}{ }_{t} \sim \operatorname{Normal}\left(0, \sigma_{t}^{*}\right)
$$

298 Here, $\varphi_{0}, \theta_{0}$, and $\alpha_{0}$ refer to the baseline survival of unfed, blood-fed and gravid 299 females respectively on a linear scale, under fixed temperature conditions of $27 \pm 2^{\circ} \mathrm{C}$ 300 (insectary standard under which An. funestus have maximum survival [52,54]), and 301 assumes no blood meal limitation. The positive impact of temperature on all three 302 life stages was represented by the coefficients $\varphi_{1}, \theta_{1}$ and $\alpha_{1}$ with an uninformative 303 gamma prior with mean 12.5 and variance of 6.25 . The coefficients $\varphi_{2}, \theta_{2}$ and $304 \alpha_{2}$ correspond to the curvilinear effect of temperature on the survival of all three 305 adult stages with their priors derived from the ratio between the linear coefficient 306 and twice optimum temperature. This formulation ensured that the optimum 307 temperature is fixed at $\left(27^{\circ} \mathrm{C}\right)$. The parameters $\varepsilon_{a}, \varepsilon_{f}, \varepsilon_{v}$ capture unexplained 308 variation associated with survival during the distinct gonotrophic stages. These error 309 terms $\left(\varepsilon^{*}\right)$ were defined by normal priors with mean of 0 and a precision $\sigma^{*}$ from a 310 gamma distribution with both shape and rate of 10 for unfed, blood-fed and gravid 311 females.

312

313

314

315

316

317

318

$$
l(t)=\frac{\exp (L(t))}{1+\exp (L(t))}
$$

Specifically, $L(t)$ is written as the function of temperature covariates:

$$
L(t)=C_{0}+C_{1} T_{(t-1)}
$$


324 Here $C_{0}$ corresponds to the baseline daily development period on a linear scale 325 defined by an informative beta prior with range defined in eq 16-17 (Table 1). The 326 coefficient $C_{1}$ explains the positive effect of temperature on larval development 327 period, with its prior values derived from an uninformative gamma prior with mean $328 \quad 0.001$ and standard deviation 0.001 .

329

330 The development time for other life history stages (eggs and pupae) and the time 331 between gonotrophic stages were assumed to be independent of temperature and 332 other environmental covariates. The numbers of individuals $\left(\mathcal{K}_{m}\right)$ graduating from one 333 stage to the next each day were modelled as a binomial process Eq 11.

$$
\mathcal{K}_{m}(t) \sim \operatorname{Binomial}\left(r_{m}, \mathcal{W}_{m-1}(t)\right)
$$

335

336 Here the rate $r_{m}$ is a development probability as defined in eq 11 for $m$ stage, with 337 assigned informative prior values as described through a generic prior in eq 16-17 338 (Table 1). Parameter $\mathcal{W}_{m-1}(t)$ refers to the number surviving the preceding life stage. 339

\section{Fecundity}

341 The number of eggs laid at each time step was drawn from a Poisson distribution 342 whose rate was the product of per-capita fecundity (number of eggs laid by blood-fed 343 An. funestus under insectary conditions $\left(b_{0}\right)$, a penalized rate for the egg survival $344\left(s_{e}\right)$, the number of gravid mosquitoes $\left(V_{(t-1)}\right)$ and ratio of females-males (assumed to 345 be 0.5$)$ as assessed at the pupae stage [19]. 346

$$
b_{t}=\exp \left(b_{0}+\varepsilon_{b, t}\right)
$$

347

$$
B(t) \sim \operatorname{Poisson}\left(0.5 b_{t} s_{e} V_{(t-1)}\right)
$$


370

371

The error term $\varepsilon_{b}$ was defined by normal prior with mean of 0 and a precision from a gamma distribution with both shape and rate of 10

\section{Observation-derived components of the Bayesian SSMs}

Observations of the abundance of adults (unfed, bloodfed, gravid) $A$ at time $t$ were modelled as a normal distribution with varying daily means à determined by the biological model and a precision $\tau$ representing observation error. We assumed a fixed coefficient of variation $(\xi)$ for the daily observation process which was assigned an uninformative prior with values between 0.1-0.9 (Table 1). The CDC light trap typically samples mosquitoes from populations of unknown size, for which the daily catch rates are difficult to quantify independently. A parameter $\vartheta$ was therefore incorporated both into the precision $\tau$ and daily varying means to account for an observed weekly periodicity in adult abundance, which was otherwise hard to interpret. This parameter was allowed to vary both by day of the week $j$ and between the two populations $k$ (2015 and 2018-19 datasets). The $v$ values were derived from a logit function $\exp (\rho) /(1+\exp (\rho))$, with $\rho$ defined from the uninformative normal prior with mean and standard deviation of 0 and 10 respectively. Therefore precision $\tau$ can be written as $\frac{1}{\left(\xi_{t} \bar{a}_{t} \vartheta_{j k}\right)^{2}}$ for all the adult stages. This mean the observation abundance was estimated as follows:

$$
A(t) \sim \operatorname{Normal}\left(\overline{\mathrm{a}}_{t} \vartheta_{j k}, \quad \frac{1}{\left(\xi_{t} \overline{\mathrm{a}}_{t} \vartheta_{j k}\right)^{2}}\right)
$$

Trap bias: The trapping method (CDC Light traps) primarily targets unfed hostseeking mosquitoes [57]. Blood fed and gravid mosquitoes are assumed to no longer host-seek, and represent a small proportion $0.5-3 \%$ of total collections of females caught $[6,22])$. To account for these biases in sampling, we added a new parameter of "trap-biasness" $\omega$ in the observation model for both precision $\tau$ and varying daily means $\bar{a}_{\eta}$. The prior values for $\omega$ were estimated from independent studies from the 
377

378

379 380

$$
A_{\eta}(t) \sim \operatorname{Normal}\left(\overline{\mathrm{a}}_{\eta t} \vartheta_{j k} \omega_{\eta}, \quad \frac{1}{\left(\xi_{t} \overline{\mathrm{a}}_{\eta t} \vartheta_{j k} \omega_{\eta}\right)^{2}}\right)
$$

381

382

383

384 385

386

387

388

389

390

391

392

393

394

395

396

397

398

399

400

401

402

403

same locations [6,58], and ranged from 0.05-0.15 (Table 1), with variations between the two life stages $\eta$. Therefore, the observation model for blood-fed and gravid $\left(A_{\eta}\right)$ was rewritten by modifying eq 14 as follows

Prior distributions: Since this model contains a large number of parameters, use of un-scaled informative priors restricted model convergence and mixing. We therefore opted for rescaled beta distributions of the informative priors [59], calibrated as follows:

$$
Y=\operatorname{Beta}(5,5)
$$

$$
X=X_{\min }+Y\left(X_{\max }-X_{\min }\right)
$$

Where $Y$ is a dummy variable that takes values in the interval $[0,1]$ with mean of 0.5 and standard deviation of 0.15 , selected to provide low likelihood at the values 0 and 1. The values of $X_{\min }$ and $X_{\max }$ define the range of the parameter of interest as dictated by the prior information. Since the information on priors was provided in form of mean $(\mu)$ and standard deviation $(\sigma)$, the values were defined as $X_{\min }, X_{\max }=$ $\mu \pm 2 \sigma$. Survival, development period, trap-biasness, variability in daily catches and fecundity parameters were all assigned priors according to Eq. 17.

\section{Model selection, model fitting and outputs}

Model fitting was done using the R statistical software version 4.0.5 [60]. Population models were fitted using a Markov Chain and Monte Carlo sampling (MCMC) algorithm via the JAGS software [61] interfaced to $R$ via the runjags package [62] (code provided in the supplementary material S1). To achieve convergence, the model with 6 chains was run in parallel for $10^{5}$ samples with a burn-in of $10^{5}$, keeping every $10^{\text {th }}$ iteration for memory-saving reasons. Convergence was assessed by visual investigation of the trace plots, prior-posterior distribution using the coda package [63], effective 
sample sizes and the Gelman Rubin diagnostic [64]. Model comparisons were done using the deviance information criterion (DIC) [65], and the ones with the lowest DIC selected as the most preferred. The predicted and observed densities of An. funestus adult females were plotted to evaluate consistent prediction biases visually (Figure S2). Posterior means and 95\% credible intervals for the key survival parameters, development period, density dependence, environmental covariates (temperature and rainfall) and fecundity were also reported to reveal different dynamical aspects of the system.

\section{Results}

Population trajectories and seasonal trends: We used a Bayesian state-space model to describe the population dynamics of wild populations of An. funestus. The full results, including summaries of posterior means for all the fitness and demographic parameters are reported in Table 1. The most parsimonious model (model-7, Table 3) included density dependence, and temperature and rainfall (current and lagged) impacts on larval survival, and the effect of temperature on larval development period. The only covariate that was not retained in the "model-7" was temperature impacts on adult survival. This model satisfactorily reconstructed the population dynamics of An. funestus in the study villages, with all environmental covariate relaxation applied based on DIC selection. Population trajectories were estimated for all six An. funestus life history and gonotrophic stages after accounting for potential impacts of environmental covariates and density dependence (Figure 2).

These trajectories reflect the annual trend in abundance spanning in periods from low or no rainfall to high rainfall. All trajectories show a relatively high abundance of $A n$. funestus right after the rainy season, followed by reduced but sustained abundance during the dry period for all the life stages. After accounting for observation biases during sampling, the observed abundance of unfed, gravid and blood-fed groups largely falls within the credible intervals of the predicted values (Figure 3 ). 
435

436

437

438

439

440

441

442

443

444

445

446

447

448

449

450

451

452

453

454

455

456

457

458

459

460

461

462

463

464

465

Survival and fecundity: Estimated An. funestus larval survival trajectories demonstrate substantial mean variability during the two seasons, with no clear pattern of seasonality (Figure 4a\&b), Table 1). Similarly, the survival trajectories of the adult stages (all gonotrophic states) were variable throughout the year, with daily survival rate ranging from 0.2 to 1.0 and not consistently differing between wet and dry seasons (Figure 4c-h, Table 1). Per capita fecundity was estimated to be between 75 and 81 eggs per female An. funestus (Table 1). While the abundance of this species fluctuated seasonally, per capita fecundity remained consistent throughout the year (Figure 4k\&l).

Temperature was an important predictor of larval survival with a curvilinear relationship $(\triangle D I C=138$, Table 3 , Figure $5 b)$, and that temperature has a positive monotonic relationship with larval development period $(\triangle \mathrm{DIC}=336$, Table 3 , Figure $5 a)$; with the larval development period estimated to last about 16 days on average. Additionally, daily rainfall was an important driver for the dynamics of An. funestus by reducing larval survival $(\triangle D I C=5605$, Table 3 , Figure $5 c)$ with a negative monotonic relationship.

Effects of density dependence: Density dependence was the only intrinsic feature incorporated in this dynamic model of An. funestus. The model was able to converge efficiently without crashing when density dependency was removed, suggesting this process plays a detectable but relatively minor role population regulation when compared with extrinsic factors $(\triangle \mathrm{DIC}=222$, Table 3 , Figure $5 e)$. To verify this, we run a simulation and discovered that the estimated density dependence was actually quite low, even when simulating with a single dataset. The model fitting process also suggested the interaction parameter $\left(\beta_{3}\right)$ between larvae density $(D)$ and one week cumulative rainfall $(Q)$ contributes to $A n$. funestus dynamics by positively increasing larval survival $(\triangle \mathrm{DIC}=38$, Table 3 , Figure $5 \mathrm{~d})$. 


\section{Discussion}

467 We have adapted advanced methods used in mainstream ecological studies and fitted 468 a state-space model (SSM) to field and laboratory data to accurately reconstruct 469 population dynamics of wild population of An. funestus. The SSM inferred the 470 trajectories of multiple life-cycle and gonotrophic stages of wild An. funestus 471 females. This allowed us to reconstruct the observed trajectories of larvae and adult 472 females for the wild An. funestus in Tanzania for the first time. This analysis 473 indicated that the dynamics of An. funestus were best explained in a model that 474 included density dependency, temperature (curvilinear relationship) and rainfall 475 (negative monotonic relationship) on larval survival, and temperature on the larval 476 development period (positive monotonic relationship). In contrast, model fit was not

477 improved by incorporating temperature dependency into adult survival (all 478 gonotrophic stages). Anopheles funestus abundance vary seasonally between wet and 479 dry but demographics rates (i.e. survivals, fecundity and development period) did not 480 vary after accounting for the impact of environmental covariates and density 481 dependence. These results are very useful for generating hypotheses about the nature 482 and relative magnitude of drivers of An. funestus population dynamics in the wild. 483 This model can be extended to include a component on malaria dynamics in humans; 484 or to compare the efficacy and effectiveness of different interventions in combination 485 or singly. This would allow more sophisticated evaluation of suitability of An. 486 funestus-specific interventions; including prediction of the potential combined effect 487 of strategies that acting at different life-cycle stages and/or target different 488 demographic processes (e.g. survival versus fecundity).

489 Extrinsic covariates such as rainfall and temperature were all hypothesised to be the 490 main drivers for the dynamics of this vector species. This study supports the 491 hypothesis that rainfall is a significant driver of the population dynamics of wild An. 492 funestus. Overall, the abundance of all life stages were relatively higher in rainy 493 compared to dry periods of the year as previously documented [22,66-68]. Rainfall 494 covariates were directly included in the larval survival model since it is the only stage 495 on which rainfall was hypothesized to have a significant impact. Daily larval survival 
as estimated by the SSM model showed high variability both within seasons and across the year. There was support for a monotonic association between rainfall and larval survival; characterized as reduction in larval survival during periods of heavy rainfall [69]. Time lags have been used to assess rainfall impacts on the dynamics of these vectors (e.g.[22]). Anopheles funestus abundance have been shown to be positively associated with the cumulative lag rainfall [22]. Here we modelled a one week cumulative rainfall to account for its effect on survival. Similar to other vectors of malaria transmission such as An. gambiae s.l, rainfall have always been considered as the main factor regulating the dynamics, despite ecological differences between the two vector species $[22,46,70,71]$.

The SSM also provided support for the hypothesis that temperature is an important driver of An. funestus dynamics; although the nature of temperature effects was complex and variable between life history stages. For example, temperature was associated with both larval survival and development, but not adult survival or fitness. Furthermore the estimated impacts of temperature on larval ecology were complex; with the SSM suggesting a curvilinear relationship with survival but a positive monotonic impact with the larval development period. Our findings validate prior studies that demonstrated that temperature had a curvilinear influence on Anopheles larval survival, with a rise in temperature above/below the optimum lowering survival $[47,72,73]$. The larval period of An. gambiae s.l. is temperature dependent [55,73]; thus our model incorporated a positive monotonic effect such that development is fastest when temperature is high and just below maximum threshold for larval development [73,74]. In our final model the effect of temperature on gonotrophic stages was not found to be an important driver for the dynamic of this species thus left out during model selection process.

Little is known about the effect of density dependence on An. funestus due to its ecology and reliance on the large semi-permanent and permanent breeding habitats [20,21]. However, density dependence is already well-known to be an important driver for dynamic of other malaria vectors like An. gambiae [25,27-29,31,67,75] and other non-malaria vectors like Aedes aegypti [76,77]. Variations in densities during 
526 the aquatic stages of An. gambiae s.l. have been found to affect adult fitness $[28,78]$.

527 The SSM model fit better fit when density dependence of larval survival was included, 528 though the relative magnitude of this process was quite small and likely to have minor 529 impact on the overall dynamics of An. funestus populations (Figure 5e). These 530 findings suggest that An. funestus populations are likely to be regulated more by extrinsic than intrinsic processes. These findings corroborate our original hypotheses 532 about density dependence having a weaker regulatory role in this species on the basis 533 of the types of larval habitats (i.e. larger and more permanent habitat $[20,79]$ ), which 534 can likely sustain higher resources and thus reduced competition than in An. gambiae 535 sl. To our knowledge, this is the first report documenting the role of density 536 dependence on the dynamics of the wild populations of An. funestus. Now that 537 colonies are becoming more feasible, more thorough investigation on the role of 538 density dependence in the dynamic of An. funestus is prerequisite.

539 In addition to highlighting potential drivers of An. funestus populations, the SSM here 540 generated plausible estimates of key demographic and life-history process in the wild. 541 Our model estimated that An. funestus larvae takes an average of 15.6-16.1 days to 542 grow from first instar larvae to pupae; which is relatively long compared to the other 543 major vectors in the An. gambiae s.l complex (9-11 days [55,72]). This apparently 544 longer development period of An. funestus may be a product of their adaptation to 545 more permanent, year-round breeding habitats that are unlikely to dry up; thus 546 reducing selection for rapid development. The SSM estimated that the daily survival 547 of wild An. funestus larvae could be as high as 0.95 , compared to the 0.83 [0.80, 548 0.86] mean daily survival rate of the known vector of malaria transmission $A n$. 549 gambiae s.l. $[72,80]$. This matches observations from insectary experiments in which 550 An. funestus larvae have higher survival than An. gambiae s.l. [19,38,81]. Given the 551 apparently higher rates of survival in An. funestus than in An. gambiae s.l., these 552 findings suggest that more lethal intervention may be required to control An. funestus 553 both at larvae and adults stages.

554 The impact of any vector control largely depends on the ecology of the specific vector 555 species. Differences in ecology between An. gambiae s.l. and An. funestus are likely 
556 to affect the relative impact of interventions. For instance, An. gambiae s.l. prefers 557 breeding in small and temporary habitats which dry up quickly when there is no 558 rainfall which is opposite to An. funestus habitats. Despite the fact that An. funestus 559 habitats are "few, fixed, and findable" and might be easily targeted for larviciding 560 [20] during the dry season, treating habitats such as rivers or bigger ponds could pose 561 logistical challenges. The persistence of An. funestus throughout the year even during 562 the driest periods suggest this vector is less seasonal compared to An. gambiae s.l. 563 which experience much more dramatic "boom and bust" dynamics in relation to 564 seasonal rains $[6,22,68]$. If interpreted together with the observation that survival 565 estimates were not seasonal, the model suggests that this species is likely responsible 566 for year-round malaria transmission throughout the year, while other species, which 567 mostly occupy temporary habitats may be responsible for any apparent seasonality in 568 transmission.

569 Models of vector population dynamics can provide a useful guide for the selection of 570 optimal vector control strategies; particular through enabling more focal investigation 571 of the benefits of seasonal or spatial targeting and use of combined versus single 572 interventions. Despite its complexity, this population dynamics model provides a 573 useful framework for investigation of the stability of An. funestus populations. With 574 additional data, this model can be further refined to include additional modifications 575 related to vector ecology and behaviour that may impact intervention impact (e.g. 576 host choice and its impacts on fitness, predation during larval or adult phase). Such 577 further elucidation may increase the predictive accuracy of this SSM in specific 578 contexts, but even the more general framework developed here have flexibility to 579 introduce stage-specific mortality effects expected from different types of vector 580 control $[16,32,33]$. For example, this framework could be used to model the impact of 581 combined interventions including those that target adult females (insecticide-treated 582 nets (ITNs), IRS) and larviciding; and assessment of how mortality varies with 583 different coverage [16,32]. An important limitation of this study is we have no idea 584 what percentage of An. funestus mosquito population is sampled by the trap, which is 585 important for understanding the relative magnitude of demographic stochasticity in 
586 modelled dynamics. This highlights the need to explicitly incorporate this source of 587 uncertainty into vector and transmission dynamics; including the need for further 588 calibration and standardization of the efficiency and biases associated with particular 589 mosquito trapping methods.

\section{Conclusions}

591 This study used Bayesian State Space Models (SSM) parameterized with empirical data 592 to quantify key demographic and fitness processes underpinning the population 593 dynamics of An. funestus in Tanzania. We report the first use of SSM to understand 594 the population dynamic of the wild vector of residual malaria transmission, An. 595 funestus in Tanzania. The model structure allowed investigation of the relative 596 importance of seasonally-varying environmental covariates (i.e. rainfall and 597 temperature) and density dependence; providing some support for both processes 598 although the magnitude of the former was much greater than the latter. The ability 599 of this model to accurately reconstruct the seasonal dynamics and demography of An. 600 funestus indicate its value for simulating the response of these populations to vectors 601 control measures applied either individually or in combination. Additionally, the 602 relatively limited evidence of seasonality in key fitness and demographic rates further 603 corroborate evidence that this vector species can facilitate efficient year-round 604 transmission of malaria. Finally, this model also highlights the clear importance of 605 accounting for regional and daily observation biases when modelling mosquito 606 population

dynamics. 
Table 1: Priors as used in the state-space population models of Anopheles funestus and the estimated posteriors mean and $95 \%$ credible intervals.

\begin{tabular}{|c|c|c|c|c|c|c|c|}
\hline \multicolumn{2}{|c|}{ Parameter } & \multicolumn{4}{|c|}{ Prior distribution } & \multicolumn{2}{|c|}{ Posterior distribution } \\
\hline Notation & Description & Type & Source & Mean & 95-percentiles & Mean & 95-percentiles \\
\hline$s_{e}$ & $\begin{array}{l}\text { Eggs daily survival } \\
\text { rate }\end{array}$ & Beta & This study & 0.794 & {$[0.619,1]$} & 0.789 & {$[0.776,0.804]$} \\
\hline$\lambda$ & $\begin{array}{l}\text { Eggs development } \\
\text { period }\end{array}$ & Beta & This study & 0.5 & {$[0.4,0.6]$} & 0.499 & {$[0.485,0.514]$} \\
\hline$\beta_{0}$ & $\begin{array}{l}\text { Baseline larval daily } \\
\text { survival }\end{array}$ & Beta & This study & 0.923 & {$[0.801,1]$} & 0.950 & {$[0.943,0.956]$} \\
\hline$C_{0}$ & $\begin{array}{l}\text { Baseline larval } \\
\text { development period }\end{array}$ & Beta & This study & 0.063 & {$[0.055,0.071]$} & 0.063 & {$[0.062,0.064]$} \\
\hline$s_{p}$ & $\begin{array}{l}\text { Pupae daily survival } \\
\text { rate }\end{array}$ & Beta & This study & 0.941 & {$[0.874,1]$} & 0.944 & {$[0.930,0.950]$} \\
\hline$p_{r}$ & $\begin{array}{l}\text { Pupae development } \\
\text { period }\end{array}$ & Beta & This study & 0.522 & {$[0.253,0.792]$} & 0.525 & {$[0.506,0.546]$} \\
\hline$\varphi_{0}$ & $\begin{array}{l}\text { Baseline unfed daily } \\
\text { survival }\end{array}$ & Beta & This study & 0.935 & {$[0.877,0.992]$} & 0.937 & {$[0.933,0.941]$} \\
\hline$a_{r}$ & $\begin{array}{l}\text { Unfed development } \\
\text { period }\end{array}$ & Beta & This study & 0.20 & {$[0.19,0.21]$} & 0.200 & {$[0.198,0.201]$} \\
\hline$\theta_{0}$ & $\begin{array}{l}\text { Baseline blood-fed } \\
\text { daily survival }\end{array}$ & Beta & This study & 0.807 & {$[0.654,0.961]$} & 0.810 & {$[0.799,0.820]$} \\
\hline$f_{r}$ & Blood-fed daily & Beta & This study & 0.25 & {$[0.05,045]$} & 0.269 & {$[0.256,0.280]$} \\
\hline
\end{tabular}




\begin{tabular}{|c|c|c|c|c|c|c|c|}
\hline & transition rate & & & & & & \\
\hline$\alpha_{0}$ & $\begin{array}{l}\text { Baseline gravid daily } \\
\text { survival }\end{array}$ & Beta & This study & 0.904 & {$[0.848,0.961]$} & 0.903 & {$[0.899,0.907]$} \\
\hline$v_{r}$ & $\begin{array}{l}\text { Gravid daily } \\
\text { transition rate }\end{array}$ & Beta & This study & 0.333 & {$[0.133,0.533]$} & 0.311 & {$[0.297,0.324]$} \\
\hline$b_{0}$ & $\begin{array}{l}\text { No. eggs/female (Per } \\
\text { capita fecundity) }\end{array}$ & Beta & This study & 80 & {$[60,100]$} & 78 & {$[75,81]$} \\
\hline$\xi$ & $\begin{array}{l}\text { Coefficient of } \\
\text { variability }\end{array}$ & Beta & $\begin{array}{c}\text { Uninformative } \\
\text { prior }\end{array}$ & 0.5 & {$[0.1,0.9]$} & 0.79 & {$[0.810,0.825]$} \\
\hline$\omega_{\eta=f}$ & $\begin{array}{l}\text { Coefficient of "Trap } \\
\text { biasness" for the } \\
\text { blood-fed }\end{array}$ & Beta & \multirow{2}{*}{$\begin{array}{l}\text { Msugupakyula } \\
\text { et al } 2020 \text { [58] } \\
\text { and Kaindoa } \\
\text { et al } 2017 \text { [6] }\end{array}$} & 0.1 & {$[0.05,0.15]$} & 0.122 & {$[0.117,0.127]$} \\
\hline$\omega_{\eta=v}$ & $\begin{array}{l}\text { Coefficient of "Trap } \\
\text { biasness" for the } \\
\text { gravid }\end{array}$ & & & $0.505^{*} \omega_{f}$ & {$[0.025,0.076]$} & 0.062 & {$[0.059,0.064]$} \\
\hline
\end{tabular}


Table 2: Priors for the intrinsic and extrinsic drivers of the population dynamic as used in the state-space model of Anopheles funestus and the estimated posteriors mean and 95\% credible intervals.

\begin{tabular}{|c|c|c|c|c|c|c|c|}
\hline \multicolumn{2}{|c|}{ Parameter } & \multicolumn{4}{|c|}{ Prior distribution } & \multicolumn{2}{|c|}{ Posterior distribution } \\
\hline Notation & Description & Type & Source & Mean & sd & Mean & 95-percentiles \\
\hline$\beta_{1}$ & $\begin{array}{l}\text { Linear coefficient for } \\
\text { rainfall on larvae } \\
\text { survival }\end{array}$ & Gamma & $\begin{array}{c}\text { Uninformative } \\
\text { prior }\end{array}$ & 0.1 & 0.05 & 0.01681 & {$[0.00604,0.0308]$} \\
\hline$\beta_{2}$ & $\begin{array}{l}\text { Density dependent } \\
\text { coefficient for larvae } \\
\text { on larvae survival }\end{array}$ & Gamma & $\begin{array}{c}\text { Uninformative } \\
\text { prior }\end{array}$ & 0.5 & 0.7 & $1.0283 e-4$ & {$[1.0 e-4,1.1205 e-4]$} \\
\hline$\beta_{3}$ & $\begin{array}{l}\text { Coefficient of } \\
\text { interaction between } \\
\text { larvae and rainfall on } \\
\text { larvae survival }\end{array}$ & Gamma & $\begin{array}{c}\text { Uninformative } \\
\text { prior }\end{array}$ & 0.9 & 0.1 & 0.9601 & {$[0.80810,0.99999]$} \\
\hline$\beta_{4}$ & $\begin{array}{l}\text { Linear coefficient for } \\
\text { temperature on } \\
\text { larvae survival }\end{array}$ & Gamma & $\begin{array}{c}\text { Uninformative } \\
\text { prior }\end{array}$ & 1 & 0.316 & 0.487 & {$[0.203,0.806]$} \\
\hline$\beta_{5}$ & $\begin{array}{l}\text { Quadratic coefficient } \\
\text { for temperature on } \\
\text { larvae survival }\end{array}$ & & $\begin{array}{l}\text { a function of } \\
\qquad \beta_{4}\end{array}$ & & & -0.00902 & {$[-0.01492,-0.00376]$} \\
\hline$C_{1}$ & $\begin{array}{l}\text { Linear coefficient for } \\
\text { temperature on } \\
\text { larvae development } \\
\text { period }\end{array}$ & Gamma & $\begin{array}{c}\text { Uninformative } \\
\text { prior }\end{array}$ & 0.001 & 0.001 & $5.362 e-4$ & {$[2.51 \mathrm{e}-8,2.311 \mathrm{e}-3]$} \\
\hline
\end{tabular}




\begin{tabular}{|c|c|c|c|c|c|c|c|}
\hline$\varphi_{1}$ & $\begin{array}{l}\text { Linear coefficient for } \\
\text { temperature on } \\
\text { unfed, survival }\end{array}$ & Gamma & $\begin{array}{c}\text { Uninformative } \\
\text { prior }\end{array}$ & 1 & 0.316 & 0.074 & {$[0.068,0.081]$} \\
\hline$\varphi_{2}$ & $\begin{array}{l}\text { Quadratic coefficient } \\
\text { for temperature on } \\
\text { unfed survival }\end{array}$ & Gamma & $\begin{array}{l}\text { a function of } \\
\varphi_{1}\end{array}$ & \multicolumn{2}{|l|}{$\varphi_{2}=\frac{\varphi_{1}}{2 * \rho}$} & $-1.378 e-3$ & {$[-1.50 e-3,-1.26 e-3]$} \\
\hline$\theta_{1}$ & $\begin{array}{l}\text { Linear coefficient for } \\
\text { temperature on } \\
\text { bloodfed survival }\end{array}$ & Gamma & $\begin{array}{c}\text { Uninformative } \\
\text { prior }\end{array}$ & 1 & 0.316 & 0.074 & {$[0.068,0.081]$} \\
\hline$\theta_{2}$ & $\begin{array}{l}\text { Quadratic coefficient } \\
\text { for temperature on } \\
\text { bloodfed survival }\end{array}$ & Gamma & $\begin{array}{l}\text { a function of } \\
\theta_{1}\end{array}$ & \multicolumn{2}{|l|}{$\theta_{2}=\frac{\theta_{1}}{2 * \rho}$} & $-1.378 e-3$ & {$[-1.50 e-3,-1.26 e-3]$} \\
\hline$\alpha_{1}$ & $\begin{array}{l}\text { Linear coefficient for } \\
\text { temperature on } \\
\text { gravid survival }\end{array}$ & Gamma & $\begin{array}{c}\text { Uninformative } \\
\text { prior }\end{array}$ & 1 & 0.316 & 0.074 & {$[0.068,0.081]$} \\
\hline$\alpha_{2}$ & $\begin{array}{l}\text { Quadratic coefficient } \\
\text { for temperature on } \\
\text { gravid survival }\end{array}$ & Gamma & $\begin{array}{l}\text { a function of } \\
\qquad \alpha_{1}\end{array}$ & \multicolumn{2}{|l|}{$\alpha_{2}=\frac{\alpha_{1}}{2 * \rho}$} & $-1.378 e-3$ & {$[-1.50 e-3,-1.26 e-3]$} \\
\hline
\end{tabular}


Table 3: Model selection: Description of all models fitted with and without environmental covariates and their corresponding delta-Deviance Information Criterion $\triangle \mathrm{DIC}$

\begin{tabular}{|c|c|c|c|c|}
\hline Model & Removed covariate(s) & Fitness measure & $\begin{array}{l}\text { Penalized Deviance } \\
\text { (pD)/DIC }\end{array}$ & $\Delta \mathrm{pD} / \mathrm{DIC}$ \\
\hline Model 1-Full & None & & 35500 & 25339 \\
\hline Model 2 & Temperature & Larval survival & 10555 & 394 \\
\hline Model 3 & Rainfall & Larval survival & 10277 & 116 \\
\hline Model 4 & $\begin{array}{l}\text { One week cummulative } \\
\text { rainfall*density dependency }\end{array}$ & Larval survival & 11886 & 1725 \\
\hline Model 5 & Density dependency & Larval survival & 11011 & 850 \\
\hline Model 6 & Temperature & $\begin{array}{l}\text { Larval development } \\
\text { period }\end{array}$ & 10873 & 712 \\
\hline Model $7^{\wedge}$ & Temperature & Adult survival & 10161 & 0 \\
\hline Model 8 & Model 7 - Temperature & Larval survival & 10299 & 138 \\
\hline Model 9 & Model 7 - Rainfall & Larval survival & 15766 & 5605 \\
\hline Model 10 & $\begin{array}{l}\text { Model } 7 \text { - } 1 \text { week rainfall:density } \\
\text { dependency }\end{array}$ & Larval survival & 10199 & 38 \\
\hline Model 11 & Model 7 - Density dependency & Larval survival & 10383 & 222 \\
\hline Model 12 & Model 7 - Temperature & Larval development & 10497 & 336 \\
\hline
\end{tabular}

^ The best model (lowest DIC/Penalized Deviance) value-model-7 followed by model-10. Model 8-12 consists of model7 minus one more environmental covariate. Model 4 involved the removal of the interaction term. 


\section{Figures:}

Figure 1: Schematic representation of the state-space population model showing different life stages compartment (circles) and flows (arrows) of Anopheles funestus. Abundance data were only available for unfed, blood-fed and gravid stages. The model assumes that once a gravid mosquito has laid eggs, they return to the unfed stage. The annotations are described in Table 1. The model incorporates six life stages (eggs, larvae, pupae, unfed, bloodfed and gravid) of An. funestus.

Figure 2: Reconstruction of the abundance trajectories for all the six life-stages. The red line indicates the mean posterior values and the respective $95 \%$ confidence intervals are shown in "sky-blue". Left column $(a, c, e, g, i, k)$ is data collected from June 2018 to May 2019 and right column $(b, d, f, h, j, l)$ is data collected from Jan-Dec 2015. The grey area indicates the period with rainfall.

Figure 3: Observed vs. model estimated values for the three adult stages with data collected using CDC light trap both in May 2018 -June 2019 (left column- a,c,d) and Jan-Dec 2015 (right column- b,d,e). Red lines are the model estimated trajectories with "sky-blue" showing their 95\% credible intervals. The blue circles are the observed values from the Light trap catches. Grey areas are the periods with rainfalls episodes.

Figure 4: Reconstruction of the survival trajectories for all the four stages (larvae, unfed, bloodfed and gravid) which were affected by the environmental covariates with the two bottom row showing the larval development period and fecundity trends. Left column (a,c,e,g,i,k) is trajectories from June 2018 to May 2019 and right column $(b, d, f, h, j, l)$ is from Jan-Dec 2015. Grey area is the period with rainfall. Y-axis shows the survival rates of different life stages and the bottom row (k\&l) shows percapita fecundity 
Figure 5: Relationship between environmental covariates and fitness parameters as estimated from the SSMs of population dynamic of Anopheles funestus.

\section{Supplementary Figures}

Figure S1: SSMs model development R codes

Figure S2: Goodness-of-fit: Observed versus predicted unfed, bloodfed and gravid densities across all populations. Adjusted R-squared, intercept and slope values are from a linear model of the predicted against observed values. Dotted lines correspond to 1:1 line. Left column $(a, c, d)$ is data collected from June 2018 to May 2019 and right column (b,d,e) is data from Jan-Dec 2015. Grey area is the period with rainfall.

Figure S3.1: Prior (orange histogram) and posterior (blue histogram) distribution of the main baseline and observational parameters in the state-space model.

Figure S3.2: Prior (orange histogram) and posterior (blue histogram) distribution of the main environmental covariates parameters in the state-space model.

\section{Declarations:}

\section{Ethics approval and consent to participate}

This study was approved by Ifakara Health Institute Review Board (Ref: IHI/IRB/No: 007-2018) and the Medical Research Coordinating Committee (MRCC) at the National Institute for Medical Research-NIMR (Ref: NIMR/HQ/R.8a/Vol.IX/2895). Individual verbal and written consent was also obtained from household owner where CDC light traps were places for collecting mosquitoes.

\section{Consent for publication}


Permission to publish was obtained from Medical Research Coordinating Committee (MRCC) at the National Institute for Medical Research (Ref. No: NIMR/HQ/P.12 VOL XXXIII/116).

\section{Availability of data and materials}

The R-codes used for model development are freely available in the supplementary file.

\section{Competing interests}

The authors declare no conflicts of interest

\section{Funding}

This work was supported by Howard Hughes Medical Institute (HHMI)-Gates Foundation (Grants: OPP1099295) and Gates Foundation (Grants: INV-002138) both awarded to FOO and HMF which support HSN.

\section{Author's contributions}

HSN, FOO, HMF and JM designed the study. HSN, IHM and EEH conducted the lab experiment and collected data used in model development. HSN and JM conducted the formal model development, fitting and validation. HSN drafted the manuscript. FOO, HMF and JM reviewed the manuscript and provide supervision. All authors accept and approve the final manuscript for publication.

\section{Acknowledgments:}

We are grateful to member of IHI-VectorSphere insectary's Joseph Mgando, Dickson, Mwasheshi, Godfrey Matanila, Neema Nombo, Rukiyah Mohammed, Johnson Kyeba and Khamis Bwanally for their contribution in different occasion during mosquito rearing, colonization and collection of wild population data. The earlier version of the model development benefited from the contributions of Luca Nelli, Fergus Chadwick, Heather McDevitt, Crinan Jarrett, Yacob Haddou and Prashanth Selvaraj. 


\section{Reference:}

1. Gillies M, Meillon D. The Anophelinae of Africa south of the Sahara (Ethiopian zoogeographical region). Sahara Ethiop Zoogeographical. 1968;343 pp.

2. Sinka ME, Bangs MJ, Manguin S, Rubio-Palis $Y$, Chareonviriyaphap T, Coetzee M, et al. A global map of dominant malaria vectors. Parasit Vectors. 2012;5:69.

3. Russell TL, Govella NJ, Azizi S, Drakeley CJ, Kachur SP, Killeen GF, et al. Increased proportions of outdoor feeding among residual malaria vector populations following increased use of insecticide-treated nets in rural Tanzania. Malar J. BioMed Central; 2011;10:80.

4. Hunt RH, Brooke BD, Pillay C, Koekemoer LL, Coetzee M. Laboratory selection for and characteristics of pyrethroid resistance in the malaria vector Anopheles funestus. Med Vet Entomol. 2005;19:271-5.

5. Braack LE, Coetzee M, Hunt RH, Biggs H, Cornel A, Gericke A. Biting pattern and host-seeking behavior of Anopheles arabiensis (Diptera: Culicidae) in northeastern South Africa. J Med Entomol. 1994;31:333-9.

6. Kaindoa EW, Matowo NS, Ngowo HS, Mkandawile G, Mmbando A, Finda M, et al. Interventions that effectively target Anopheles funestus mosquitoes could significantly improve control of persistent malaria transmission in south-eastern Tanzania. PLoS One. 2017;12.

7. Lwetoijera D, Harris C, Kiware SS, Dongus S, Devine GJ, McCall PJ, et al. Increasing role of Anopheles funestus and Anopheles arabiensis in malaria transmission in the Kilombero Valley, Tanzania. Malar J. 2014;13:331.

8. Garrett-Jones C, Shidrawi GR. Malaria vectorial capacity of a population of Anopheles gambiae: an exercise in epidemiological entomology. Bull World Health Organ. 1969;40:531-45.

9. Seyoum A, Sikaala CH, Chanda J, Chinula D, Ntamatungiro AJ, Hawela M, et al. Human exposure to anopheline mosquitoes occurs primarily indoors, even for users of insecticide-treated nets in Luangwa Valley, South-east Zambia. Parasit Vectors. 2012;5:101.

10. Riveron JM, Chiumia M, Menze BD, Barnes KG, Irving H, Ibrahim SS, et al. Rise of multiple insecticide resistance in Anopheles funestus in Malawi: A major concern for malaria vector control. Malar J. 2015;

11. Hunt RH, Edwardes M, Coetzee M. Pyrethroid resistance in southern African Anopheles funestus extends to Likoma Island in Lake Malawi. Parasites and Vectors. 2010;3.

12. McCann RS, Ochomo E, Bayoh MN, Vulule JM, Hamel MJ, Gimnig JE, et al. Reemergence of Anopheles funestus as a vector of Plasmodium falciparum in Western 
Kenya after long-term implementation of insecticide-treated bed nets. Am J Trop Med Hyg. 2014;

13. Bayoh MN, Mathias DK, Odiere MR, Mutuku FM, Kamau L, Gimnig JE, et al. Anopheles gambiae: historical population decline associated with regional distribution of insecticide-treated bed nets in western Nyanza Province, Kenya. Malar J. 2010;9:62.

14. Killeen GF, Seyoum A, Sikaala C, Zomboko AS, Gimnig JE, Govella NJ, et al. Eliminating malaria vectors. Parasit Vectors. 2013;6:172.

15. Okumu F, Finda M. Key Characteristics of Residual Malaria Transmission in Two Districts in South-Eastern Tanzania-Implications for Improved Control. J Infect Dis. 2021;223:S143-54.

16. Fillinger U, Kannady K, William G, Vanek MJ, Dongus S, Nyika D, et al. A tool box for operational mosquito larval control: Preliminary results and early lessons from the Urban Malaria Control Programme in Dar es Salaam, Tanzania. Malar J. 2008;7:1-25.

17. Killeen GF, Chitnis N, Moore SJ, Okumu FO. Target product profile choices for intra-domiciliary malaria vector control pesticide products: Repel or kill? Malar J. 2011;10.

18. Griffin JT, Hollingsworth TD, Okell LC, Churcher TS, White M, Hinsley W, et al. Reducing Plasmodium falciparum malaria transmission in Africa: A model-based evaluation of intervention strategies. PLoS Med. 2010;7.

19. Ngowo HS, Hape EE, Matthiopoulos J, Okumu FO. Fitness Characteristics of the Malaria Vector, Anopheles Funestus, During an Attempted Laboratory Colonization. Malar J. BioMed Central; 2020;20:148.

20. Nambunga IH, Ngowo HS, Mapua SA, Hape EE, Msugupakulya BJ, Msaky DS, et al. Aquatic habitats of the malaria vector Anopheles funestus in rural south-eastern Tanzania. Malar J. BioMed Central; 2020;19:1-11.

21. Gimnig JE, Ombok M, Kamau L, Hawley WA. Characteristics of Larval Anopheline (Diptera: Culicidae) Habitats in Western Kenya. Source J Med Entomol J Med Entomol. 2001;38:282-8.

22. Ngowo HS, Kaindoa EW, Matthiopoulos J, Ferguson HM, Okumu FO. Variations in household microclimate affect outdoor-biting behaviour of malaria vectors. Wellcome Open Res. 2017;2:102.

23. Minakawa N, Sonye G, Mogi M, Yan G, Communication S. Habitat characteristics of Anopheles gambiae s. S . larvae in a Kenyan highland. Med Vet Entomol. 2004;18:3015 .

24. Kabbale FG, Akol AM, Kaddu JB, Onapa AW. Biting patterns and seasonality of Anopheles gambiae sensu lato and Anopheles funestus mosquitoes in Kamuli District, 
Uganda. Parasit Vectors. 2013;6:340.

25. Russell TL, Lwetoijera DW, Knols BGJ, Takken W, Killeen GF, Ferguson HM. Linking individual phenotype to density-dependent population growth: the influence of body size on the population dynamics of malaria vectors. Proc R Soc B Biol Sci. 2011;278:3142-51.

26. Nowicki P, Bonelli S, Barbero F, Balletto E. Relative importance of densitydependent regulation and environmental stochasticity for butterfly population dynamics. Oecologia. 2009;161:227-39.

27. Gimnig JE, Ombok M, Otieno S, Michael G, Vulule JM, Walker ED, et al. DensityDependent Development of Anopheles gambiae (Diptera : Culicidae) Larvae in Artificial Habitats. J Med Entomol. 2002;

28. Ng'habi, John B, Nkwengulila G, Knols BGJ, Killeen GF, Ferguson HM. Effect of larval crowding on mating competitiveness of Anopheles gambiae mosquitoes. Malar J. 2005;4:1-9.

29. Koenraadt CJM, Majambere S, Hemerik L, Takken W. The effects of food and space on the occurrence of cannibalism and predation among larvae of Anopheles gambiae s.l. Entomol Exp Appl. John Wiley \& Sons, Ltd; 2004;112:125-34.

30. Charlwood JD. May the force be with you: measuring mosquito fitness in the field. Ecol Asp Appl Genet Modif Mosquitoes. 2003;2:47-62.

31. Henderson PA, Magurran AE. Direct evidence that density-dependent regulation underpins the temporal stability of abundant species in a diverse animal community. Proc R Soc B Biol Sci. 2014;281.

32. Viana M, Ng'habi K, Lyimo I, Ferguson HM, Matthiopoulos J, Killeen G. Mesocosm experiments reveal the impact of mosquito control measures on malaria vector life history and population dynamics. Sci Rep. 2018;8:1-12.

33. Viana M, Hughes A, Matthiopoulos J, Ranson H, Ferguson HM. Delayed mortality effects cut the malaria transmission potential of insecticide-resistant mosquitoes. Proc Natl Acad Sci U S A. 2016;113:8975-80.

34. Lyimo IN, Haydon DT, Russell TL, Mbina KF, Daraja AA, Mbehela EM, et al. The impact of host species and vector control measures on the fitness of African malaria vectors. Proc Biol Sci. 2013;280:20122823.

35. Mweresa CK, Omusula P, Otieno B, van Loon JJA, Takken W, Mukabana WR. Molasses as a source of carbon dioxide for attracting the malaria mosquitoes Anopheles gambiae and Anopheles funestus. Malar J. 2014;13:160.

36. Lyimo IN, Haydon DT, Mbina KF, Daraja AA, Mbehela EM, Reeve R, et al. The fitness of African malaria vectors in the presence and limitation of host behaviour. Malar J. 2012;11:1-12. 
37. Ferguson HM, Ng'habi KR, Walder T, Kadungula D, Moore SJ, Lyimo I, et al. Establishment of a large semi-field system for experimental study of African malaria vector ecology and control in Tanzania. Malar J. 2008;7:158.

38. Okoye PN, Brooke BD, Hunt RH, Coetzee M. Relative developmental and reproductive fitness associated with pyrethroid resistance in the major southern African malaria vector, Anopheles funestus. Bull Entomol Res. 2007;97:599-605.

39. Newman KB, Buckland ST, Lindley ST, Thomas L, Fernández C. Hidden process models for animal population dynamics. Ecol Appl. 2006;16:74-86.

40. Millar R. Bayesian state-space modeling of age-structured data: fitting a model is just the beginning. Can J Fish Aquat Sci. 2000;50:43-50.

41. Viana M, Cleaveland S, Matthiopoulos J, Halliday J, Packer C, Craft ME, et al. Dynamics of a morbillivirus at the domestic-wildlife interface: Canine distemper virus in domestic dogs and lions. Proc Natl Acad Sci. 2015;112:1464-9.

42. Rivot $\mathrm{E}$, Prévost $\mathrm{E}$, Parent $\mathrm{E}$, Baglinière JL. A Bayesian state-space modelling framework for fitting a salmon stage-structured population dynamic model to multiple time series of field data. Ecol Modell. 2004;179:463-85.

43. Mboera LEG. Sampling techniques for adult Afrotropical malaria vectors and their reliability in the estimation of entomological inoculation rate. Tanzan Health Res Bull. 2005;7:117-24.

44. Gillies MT. The duration of the gonotrophic cycle in Anopheles gambiae and Anopheles funestus, with a note on the efficiency of hand catching. East Afr Med J. 1953;30:129-35.

45. Rúa GL, Quiñones ML, Vélez ID, Zuluaga JS, Rojas W, Poveda G, et al. Laboratory estimation of the effects of increasing temperatures on the duration of gonotrophic cycle of Anopheles albimanus (Diptera: Culicidae). Mem Inst Oswaldo Cruz. 2005;100:515-20.

46. Fillinger U, Sonye G, Killeen GF, Knols BGJ, Becker N. The practical importance of permanent and semipermanent habitats for controlling aquatic stages of Anopheles gambiae sensu lato mosquitoes: Operational observations from a rural town in western Kenya. Trop Med Int Heal. 2004;

47. Sciences B, Laboratories S, Bayoh MN, Lindsay SW. Temperature-related duration of aquatic stages of the Afrotropical malaria vector mosquito Anopheles gambiae in the laboratory. Med Vet Entomol. 2004;18:174-9.

48. Lyimo., Takken W, Koella JC. Effect of rearing temperature and larval density on larval survival, age at pupation and adult size of Anopheles gambiae. Entomol Exp Appl. 1992;63:265-71.

49. Beier JC, Copeland R, Oyaro C, Masinya a, Odago WO, Oduor S, et al. Anopheles 
gambiae complex egg-stage survival in dry soil from larval development sites in western Kenya. J Am Mosq Control Assoc. 1990;6:105-9.

50. Koenraadt CJM, Majambere S, Hemerik L, Takken W. Cannibalism and predation among larvae of Anopheles gambiae s.l. Entomol Exp Appl. 2004;112:125-34.

51. Paaijmans KP, Heinig RL, Seliga RA, Blanford JI, Blanford S, Murdock CC, et al. Temperature variation makes ectotherms more sensitive to climate change. Glob Chang Biol. John Wiley \& Sons, Ltd; 2013;19:2373-80.

52. Paaijmans KP, Imbahale SS, Thomas MB, Takken W. Relevant microclimate for determining the development rate of malaria mosquitoes and possible implications of climate change. Malar J. 2010;9:196.

53. Blanford JI, Blanford S, Crane RG, Mann ME, Paaijmans KP, Schreiber K V, et al. Implications of temperature variation for malaria parasite development across Africa. Sci Rep. 2013;3:1300.

54. Paaijmans KP, Thomas MB. The influence of mosquito resting behaviour and associated microclimate for malaria risk. Malar J. 2011;10:183.

55. Kirby MJ, Lindsay SW. Effect of temperature and inter-specific competition on the development and survival of Anopheles gambiae sensu stricto and An. arabiensis larvae. Acta Trop. 2009;109:118-23.

56. Paaijmans KP, Blanford S, Bell AS, Blanford JI, Read AF, Thomas MB. Influence of climate on malaria transmission depends on daily temperature variation. Proc Natl Acad Sci U S A. 2010;107:15135-9.

57. Mboera L. Sampling techniques for adult Afrotropical malaria vectors and their reliability in the estimation of entomological inoculation rate. Tanzan J Health Res. National Institute for Medical Research; 2006;7:117-24.

58. Msugupakulya BJ, Kaindoa EW, Ngowo HS, Kihonda JM, Kahamba NF, Msaky DS, et al. Preferred resting surfaces of dominant malaria vectors inside different house types in rural south - eastern Tanzania. Malar J. BioMed Central; 2020;1-15.

59. Gelman A, Jakulin A, Pittau MG, Su YS. A weakly informative default prior distribution for logistic and other regression models. Ann Appl Stat. 2008;2:1360-83.

60. R Development Core Team. R: A language and environment for statistical computing. R Found. Stat. Comput. 2021.

61. Plummer M. JAGS : A Program for Analysis of Bayesian Graphical Models Using Gibbs Sampling JAGS : Just Another Gibbs Sampler. 2003;

62. Denwood MJ. runjags: An R Package Providing Interface Utilities, Model Templates, Parallel Computing Methods and Additional Distributions for MCMC Models in JAGS . J Stat Softw. 2016; 
63. Plummer M, Best N, Cowles K, Vines K. CODA: Convergence Diagnosis and Output Analysis for MCMC. R News. 2006;

64. Gelman A, Rubin DB. Inference from iterative simulation using multiple sequences. Stat Sci. 1992;

65. Spiegelhalter DJ, Best NG, Carlin BP, Linde A van der. Bayesian Measures of Model Complexity and Fit. J R Stat Soc Ser C, Appl Stat. 2002;64:583-639.

66. Kreppel KS, Viana M, Main BJ, Johnson PCD, Govella NJ, Lee Y, et al. Emergence of behavioural avoidance strategies of malaria vectors in areas of high LLIN coverage in Tanzania. Sci Rep. Nature Publishing Group UK; 2020;10:1-11.

67. Smith T, Charlwood JD, Takken W, Tanner M, Spiegelhalter DJ. Mapping the densities of malaria vectors within a single village. Acta Trop. 1995;59:1-18.

68. Charlwood JD, Vij R, Billingsley PF. Dry season refugia of malaria-transmitting mosquitoes in a dry savannah zone of east Africa. Am J Trop Med Hyg. 2000;62:72632.

69. Kelly-Hope, A L, Hemingway J, McKenzie FE. Environmental factors associated with the malaria vectors Anopheles gambiae and Anopheles funestus in Kenya. Malar J. 2009;8:268.

70. Lyons CL, Coetzee M, Terblanche JS, Chown SL. Thermal limits of wild and laboratory strains of two African malaria vector species, Anopheles arabiensis and Anopheles funestus. Malar J. 2012;11:226.

71. Zhou G, Munga S, Minakawa N, Githeko AK, Yan G. Spatial relationship between adult malaria vector abundance and environmental factors in western Kenya highlands. Am J Trop Med Hyg. 2007;77:29-35.

72. Lyimo EO, Takken W, Koella JC. Effect of rearing temperature and larval density on larval survival, age at pupation and adult size of Anopheles gambiae. Entomol Exp Appl. 1992;63:265-71.

73. Paaijmans KP, Huijben S, Githeko AK, Takken W. Competitive interactions between larvae of the malaria mosquitoes Anopheles arabiensis and Anopheles gambiae under semi-field conditions in western Kenya. Acta Trop. 2009;109:124-30.

74. Lyons CL, Coetzee M, Chown SL. Stable and fluctuating temperature effects on the development rate and survival of two malaria vectors, Anopheles arabiensis and Anopheles funestus. Parasit Vectors. 2013;6:104.

75. Muriu SM, Coulson T, Mbogo CM, Godfray HCJ. Larval density dependence in Anopheles gambiae s.s., the major African vector of malaria. Boots M, editor. J Anim Ecol. 2013;82:166-74.

76. Yang GJ, Brook BW, Whelan PI, Cleland S, Bradshaw CJA. Endogenous and exogenous factors controlling temporal abundance patterns of tropical mosquitoes. 
Ecol Appl. John Wiley \& Sons, Ltd; 2008;18:2028-40.

77. Hancock PA, White VL, Callahan AG, Godfray CHJ, Hoffmann AA, Ritchie SA. Density-dependent population dynamics in Aedes aegypti slow the spread of wMel Wolbachia. J Appl Ecol. John Wiley \& Sons, Ltd; 2016;53:785-93.

78. Porretta D, Mastrantonio V, Crasta G, Bellini R, Comandatore F, Rossi P, et al. Intra-instar larval cannibalism in Anopheles gambiae (s.s.) and Anopheles stephensi (Diptera: Culicidae). Parasites and Vectors. BioMed Central; 2016;9:1-9.

79. Tuno N, Githeko A, Yan G, Takagi M. Interspecific variation in diving activity among Anopheles gambiae Giles, An. arabiensis Patton, and An. funestus Giles (Diptera: Culicidae) larvae. J Vector Ecol. 2007;32:112-7.

80. Matthews J, Bethel A, Osei G. An overview of malarial Anopheles mosquito survival estimates in relation to methodology. Parasites and Vectors. BioMed Central; 2020;13:1-12.

81. Takken W, Charlwood JD, Billingsley PF, Gort G. Dispersal and survival of Anopheles funestus and A. gambiae s.l. (Diptera: Culicidae) during the rainy season in southeast Tanzania. Bull Entomol Res. 1998;88:561. 


\section{Figures}

\section{Figure 1}

Schematic representation of the state-space population model showing different life stages compartment (circles) and flows (arrows) of Anopheles funestus. Abundance data were only available for unfed, bloodfed and gravid stages. The model assumes that once a gravid mosquito has laid eggs, they return to the unfed stage. The annotations are described in Table 1. The model incorporates six life stages (eggs, larvae, pupae, unfed, bloodfed and gravid) of An. funestus. 

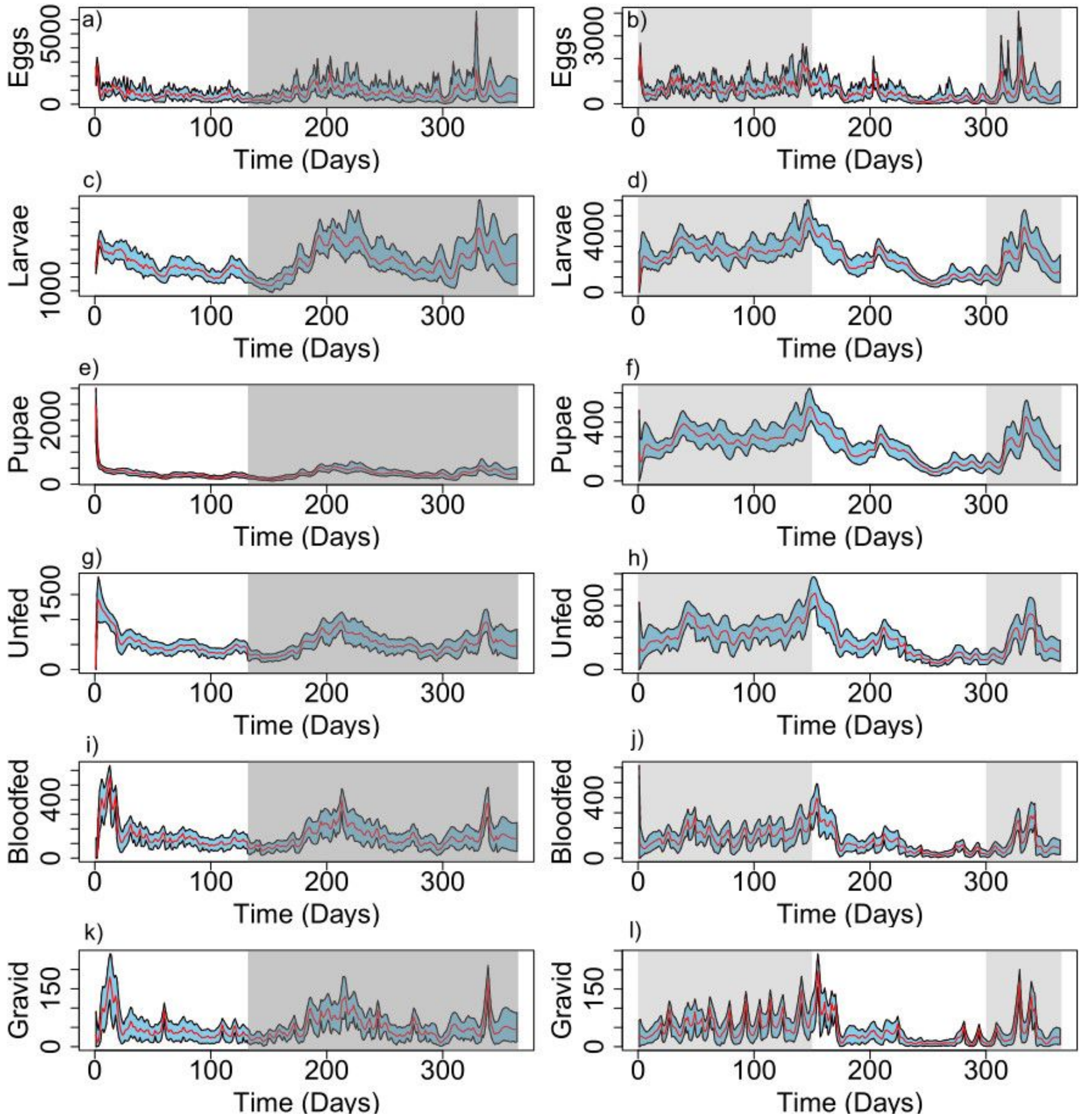

Figure 2

Reconstruction of the abundance trajectories for all the six life-stages. The red line indicates the mean posterior values and the respective $95 \%$ confidence intervals are shown in "sky-blue". Left column (a,c,e,g,i,k) is data collected from June 2018 to May 2019 and right column (b,d,f,h,j,l) is data collected from Jan-Dec 2015. The grey area indicates the period with rainfall. 

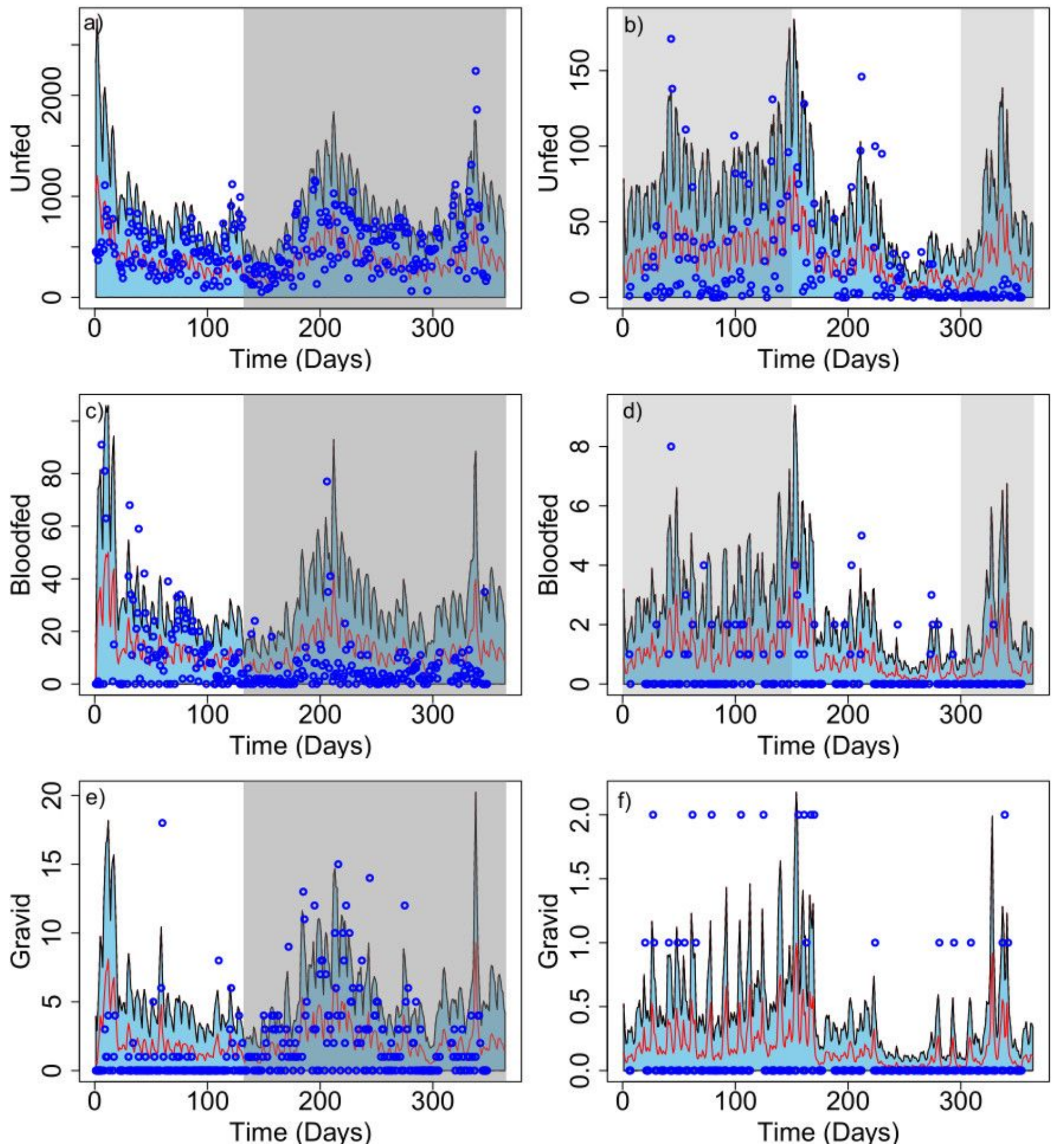

Figure 3

Observed vs. model estimated values for the three adult stages with data collected using CDC light trap both in May 2018 - June 2019 (left column- a,c,d) and Jan-Dec 2015 (right column-b,d,e). Red lines are the model estimated trajectories with "sky-blue" showing their $95 \%$ credible intervals. The blue circles are the observed values from the Light trap catches. Grey areas are the periods with rainfalls episodes. 

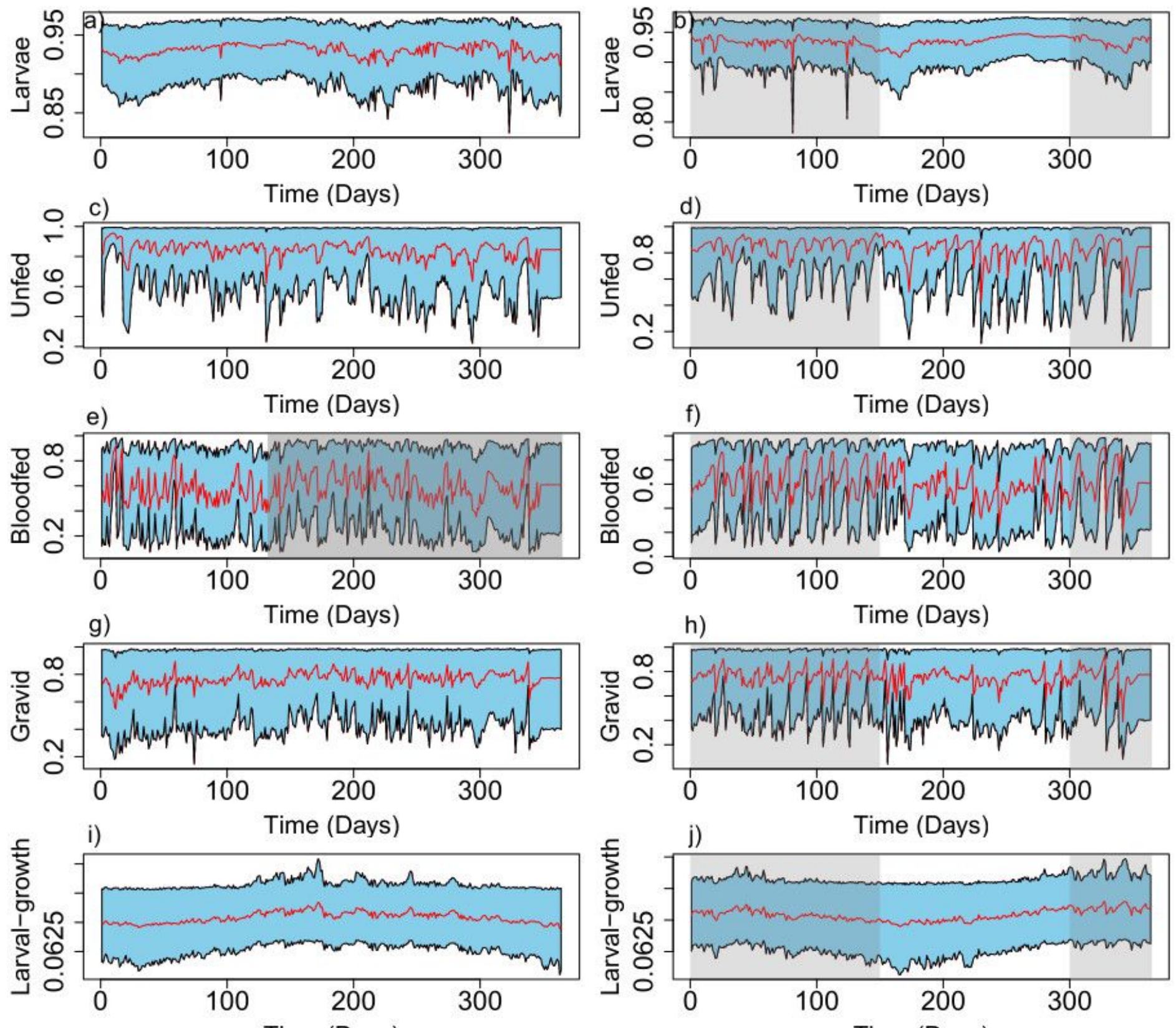

k) Time (Days)

I) Time (Days)
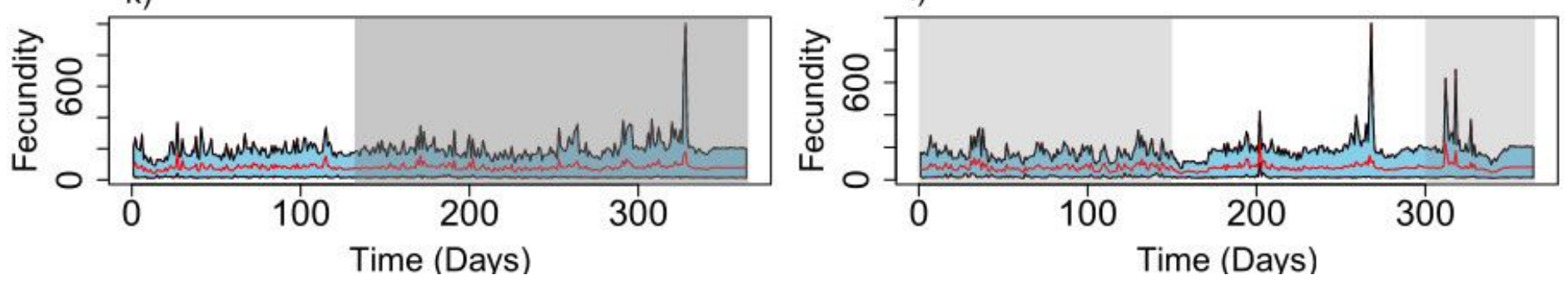

Figure 4

Reconstruction of the survival trajectories for all the four stages (larvae, unfed, bloodfed and gravid) which were affected by the environmental covariates with the two bottom row showing the larval development period and fecundity trends. Left column (a,c,e,g,i,k) is trajectories from June 2018 to May 2019 and right column (b,d,f,h,j,l) is from Jan-Dec 2015. Grey area is the period with rainfall. Y-axis shows the survival rates of different life stages and the bottom row $(k \& l)$ shows per-capita fecundity 
Growth rate vs temperature
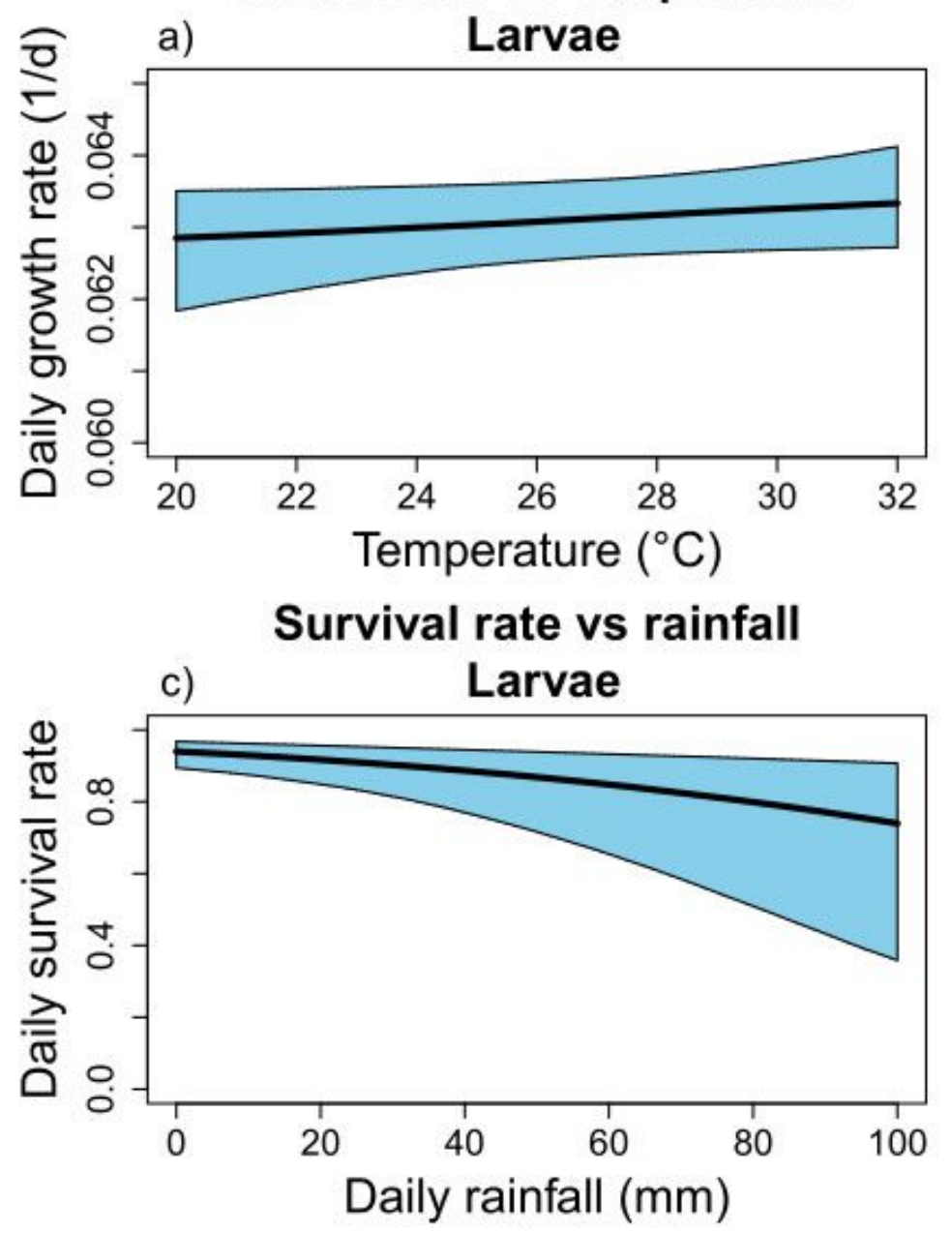

e) Survival rate vs Larval density

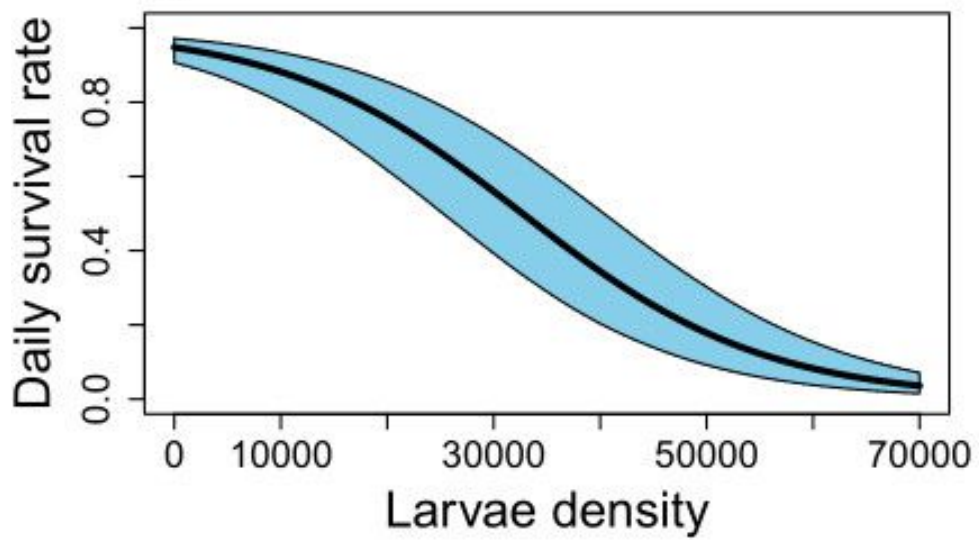

Survival rate vs temperature

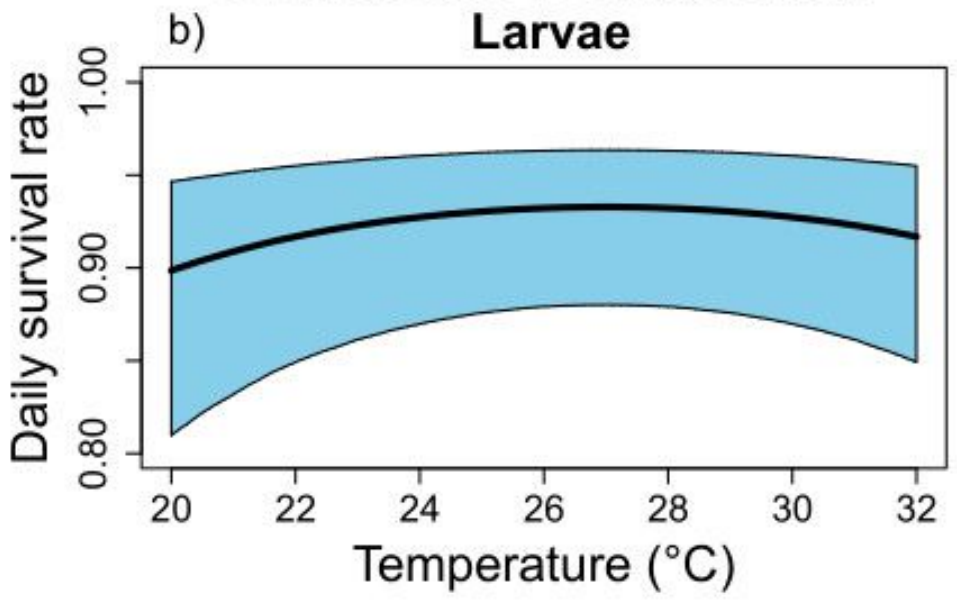

Survival rate vs cumm_rainfall

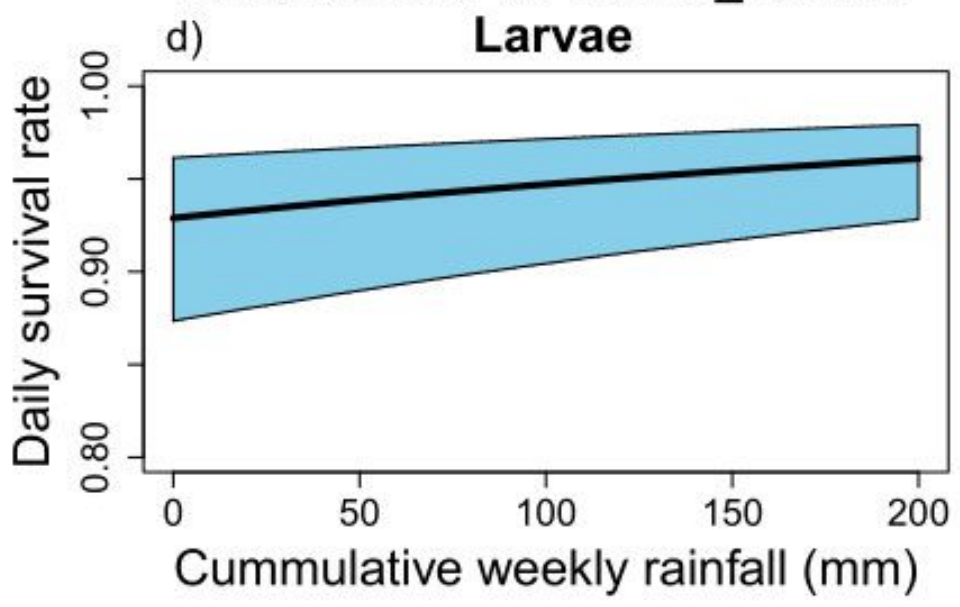

Figure 5

Relationship between environmental covariates and fitness parameters as estimated from the SSMs of population dynamic of Anopheles funestus.

\section{Supplementary Files}


This is a list of supplementary files associated with this preprint. Click to download.

- NgowoetalSupplementarylnformation.pdf 